\title{
The vacuole-targeting fungicidal activity of amphotericin $B$ against the pathogenic fungus Candida albicans and its enhancement by allicin
}

\begin{abstract}
Hasibagan Borjihan $^{1}$, Akira Ogita ${ }^{1,2}$, Ken-ichi Fujita ${ }^{1}$, Eiji Hirasawa ${ }^{1}$ and Toshio Tanaka ${ }^{1}$
In this study, the vacuole disruptive activity was evaluated as a cause of amphotericin B (AmB) lethality against the pathogenic fungus Candida albicans in terms of its enhancement by allicin, an allyl-sulfur compound from garlic. Vacuole disruption was observed in parallel to AmB-induced cell death when the antibiotic was used at a lethal concentration and at a non-lethal concentration in combination with allicin. Allicin did not enhance AmB-induced cell death and the accompanying vacuole disruption when the cells were incubated with exogenous ergosterol for its enrichment in the vacuole. The vacuoles isolated from intact cells could be directly disrupted by the action of AmB to the same extent in the absence and presence of allicin, whereas the organelles isolated from ergosterol-enriched cells were resistant to its direct disruptive action. AmB was similarly incorporated into the fungal cytoplasm in cells with or without ergosterol enrichment, supporting the fact that AmB-induced vacuole disruption depends on its direct disruptive action on the organelle. In agreement with these findings, allicin was found to inhibit ergosterol transport from the plasma membrane to the cytoplasm, which is considered to be a cellular protective response to AmB-induced vacuole disruption in S. cerevisiae. Our study suggests that AmB lethality against $C$. albicans depends at least in part on its vacuole disruptive activity under the physiological condition permissive for invasive growth of the fungus. The Journal of Antibiotics (2009) 62, 691-697; doi:10.1038/ja.2009.103; published online 30 October 2009
\end{abstract}

Keywords: amphotericin B; allicin; Candida albicans; vacuole

\section{INTRODUCTION}

Candida albicans is a ubiquitous fungus, which is normally found on the skin, and also in the mouth, throat, stomach, rectum and vagina; this fungus causes candidiasis as a result of its proliferation in any of these mammalian organs. ${ }^{1}$ Medical treatment for candidiasis includes chemotherapy using amphotericin B (AmB; Figure 1), a typical polyene macrolide antibiotic that is derived from the actinomycete Streptomyces nodosus. ${ }^{2,3} \mathrm{AmB}$ binds to ergosterol in the fungal plasma membrane and induces lethal damage by altering plasma membrane permeability. ${ }^{4}$ However, the AmB-induced lethal damage cannot be simply explained by the disturbance in plasma membrane ion transfer function because the leakage of $\mathrm{K}^{+}$results in various secondary effects, including the inhibition of protein synthesis. ${ }^{5}$ Moreover, the involvement of additional cytotoxic effects in AmB lethality is supported by the fact that the leakage of $\mathrm{K}^{+}$is not necessarily accompanied by the loss of cell viability in C. albicans. ${ }^{6}$ Oxidative stress induction is considered to be another AmB-induced toxic event in the cells of this pathogenic fungus. ${ }^{2,7}$ In our recent study, we observed vacuole membrane fragmentation in Saccharomyces cerevisiae cells on incuba- tion with $\mathrm{AmB}$ in distilled water, in which the organelle actively functions for cellular ion homeostasis and osmoregulation. ${ }^{8}$ In addition to the alteration in plasma membrane permeability in S. cerevisiae, AmB lethality could be attributed, at least in part, to its direct disruptive action on vacuoles.

Allicin (diallyl thiosulfinate) (Figure 1) exerts various therapeutic effects that could be applicable for protection against the proliferation of pathogenic microbes as well as malignant tumor cells. ${ }^{9,10}$ This allylsulfur compound is also of clinical interest because of its beneficial effects on neutral lipid metabolism and its inhibitory effect on platelet aggregation. ${ }^{11,12}$ We recently reported its enhancement effect on the fungicidal activities of $\mathrm{AmB}$ and polymyxin $\mathrm{B}$ (PMB), which is a bactericidal antibiotic, against various fungal strains. ${ }^{8,13,14}$ Allicin selectively enhanced the vacuole disruptive activity but not the plasma membrane-targeting activity of these antibiotics against $S$. cerevisiae. The enhancement effect of allicin on AmB lethality could be elucidated by its inhibitory effect on ergosterol transport from the plasma membrane to the vacuole membrane that occurs as a cellular response to protect against the direct disruptive action of the antibiotic on the

${ }^{1}$ Department of Biology and Geosciences, Graduate School of Science, Osaka City University, 3-3-138 Sugimoto, Sumiyoshi-ku, Osaka, Japan and ${ }^{2}$ Research Center for Urban Health and Sports, Osaka City University, 3-3-138 Sugimoto, Sumiyoshi-ku, Osaka, Japan

Correspondence: Professor T Tanaka, Department of Biology and Geosciences, Graduate School of Science, Osaka City University, 3-3-138 Sugimoto, Sumiyoshi-ku, Osaka, 5588585, Japan.

E-mail: tanakato@sci.osaka-cu.ac.jp

Received 6 July 2009; revised 1 October 2009; accepted 8 October 2009; published online 30 October 2009 


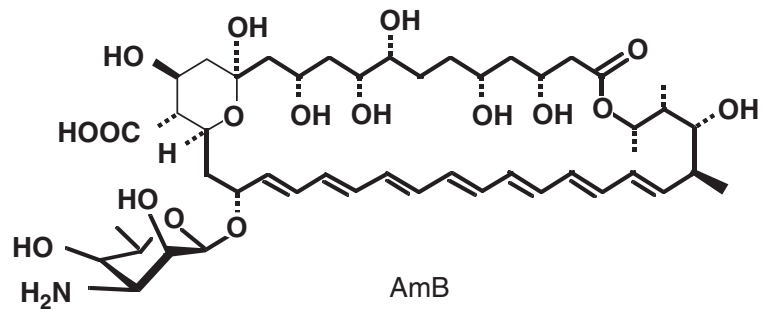<smiles>C=CCSS(=O)CC=C</smiles>

allicin organelle. ${ }^{15}$ In a recent study, it was proposed that allicin could be used to enhance AmB lethality against $C$. albicans on the basis of the in vivo experiment conducted using a murine model of candidiasis. ${ }^{16}$ They also proposed that plasma membrane phospholipid peroxidation, which is slightly provoked by the action of $\mathrm{AmB}$ alone and is markedly enhanced by the combined actions of $\mathrm{AmB}$ and allicin, is the most promising effect of allicin as an AmB enhancer. However, because their in vitro experiment, as in the case of our study, was conducted in distilled water or mineral salt medium at $30^{\circ} \mathrm{C}$, further studies are required to determine whether the enhancement effect of allicin indeed depends on such a cell surface oxidative event in vivo.

In this study, we attempted to examine the enhancement effect of allicin on the fungicidal activity of AmB against C. albicans cells in RPMI 1640 medium at $37^{\circ} \mathrm{C}$. We focused our attention on vacuole disruption as well as oxidative stress induction during the course of cell death caused by the combined actions of AmB and allicin. We also examined the mechanism underlying the enhancement effect of allicin on one of these toxic events in C. albicans cells by using methods described in our previous experiments with $S$. cerevisiae.

\section{MATERIALS AND METHODS}

\section{Measurement of cell growth and viability}

C. albicans NBRC 1061 (formerly C. albicans IFO 1061) was used in the following experiments to examine the effects of $\mathrm{AmB}$ and allicin on cell growth, cell viability and other physiological properties. ${ }^{8}$ The fungal cells were precultivated in YPD medium containing $1 \%$ yeast extract (Difco Laboratories, Detroit, MI, USA), 2\% Bacto-peptone (Difco Laboratories) and 2\% glucose at $30^{\circ} \mathrm{C}$ with vigorous shaking. Unless otherwise stated, cells from the overnight culture in YPD medium were collected by centrifugation, washed twice with RPMI 1640 medium with L-glutamine ${ }^{17}$ (RPMI 1640 medium) and suspended in the medium to obtain a final cell density of $1 \times 10^{7}$ cells ml ${ }^{-1}$. Cells were then incubated in the absence and presence of each compound with vigorous shaking at $37^{\circ} \mathrm{C}$. Viable cell number was determined by counting colony forming units after 24 -h incubation on YPD agar plate at $30^{\circ} \mathrm{C}$.

\section{Vacuole staining}

Vacuoles were visualized by staining with the fluorescent probe FM4-64 as follows. ${ }^{8}$ Cells from the overnight culture in YPD medium were suspended in a freshly prepared medium to obtain a cell density of $1 \times 10^{7} \mathrm{cells}^{-1}$. After incubation with $5 \mu \mathrm{M}$ FM4- 64 at $30^{\circ} \mathrm{C}$ for $30 \mathrm{~min}$, the cells were collected by centrifugation, washed twice with RPMI 1640 medium and suspended in the medium at a final cell density of $1 \times 10^{7}$ cells ml ${ }^{-1}$. The cells were incubated in the absence and presence of each compound with vigorous shaking at $37^{\circ} \mathrm{C}$ for $60 \mathrm{~min}$, and were then observed under a phase-contrast microscope and a fluorescence microscope with excitation at $520-550 \mathrm{~nm}$ and emission at $580 \mathrm{~nm}$.

\section{Vacuole isolation}

The vacuoles were isolated from C. albicans cells by using previously described methods ${ }^{18-20}$ with slight modifications ${ }^{15}$ as follows. Cells from the overnight culture in YPD medium were collected by centrifugation and suspended in spheroplasting buffer $(50 \mathrm{~mm}$ Tris- $\mathrm{HCl}, \mathrm{pH} 7.5 ; 1 \mathrm{~m}$ sorbitol; $10 \mathrm{~mm}$ sodium azide) with $0.5 \%$ 2-mercaptoethanol to obtain a cell density of $1 \times 10^{9}$ cells ml ${ }^{-1}$. After the addition of Yeast Lytic Enzyme at $6 \mathrm{mg} \mathrm{ml}^{-1}$, the cells were converted to spheroplasts by incubation at $30^{\circ} \mathrm{C}$ for $60 \mathrm{~min}$. The spheroplasts were then collected by centrifugation, washed with vacuole isolation buffer ( $10 \mathrm{~mm}$ sodium citrate, $\mathrm{pH} 6.8 ; 0.6 \mathrm{~m}$ sorbitol) and carefully suspended in the buffer at a final density of $5 \times 10^{9} \mathrm{cells} \mathrm{ml}^{-1}$. All the subsequent procedures were carried out on ice. The spheroplasts were homogenized with 20 strokes of a Dounce homogenizer. The homogenate $(15 \mathrm{ml})$ was transferred into a centrifugation tube and was gently overlaid first with $10 \mathrm{ml}$ of vacuole isolation buffer containing 7\% Ficoll and next with $10 \mathrm{ml}$ of the buffer containing $8 \%$ Ficoll. After centrifugation $(3000 \mathrm{~g})$ at $4{ }^{\circ} \mathrm{C}$ for $30 \mathrm{~min}$, the vacuoles at the $7-0 \%$ Ficoll interface were collected.

\section{Assay of reactive oxygen species production}

The production of reactive oxygen species (ROS) such as $\mathrm{O}_{2}{ }^{-}$and $\mathrm{H}_{2} \mathrm{O}_{2}$ was determined by our previously described method based on the intracellular deacylation and oxidation of $2^{\prime}, 7^{\prime}$-dichlorodihydrofluorescein diacetate (DCFH-DA) to the corresponding fluorescent compound. ${ }^{21}$ Isoprenoid farnesol $(\mathrm{FOH})$ was used as a positive control to enhance intracellular ROS production. Cells from the overnight culture in YPD medium were collected by centrifugation, suspended in the medium to obtain a cell density of $1 \times 10^{7}$ cells ml ${ }^{-1}$ and incubated with $40 \mu \mathrm{M}$ DCFH-DA at $30^{\circ} \mathrm{C}$ for $60 \mathrm{~min}$. The cells were then collected by centrifugation and suspended in an equal volume of RPMI 1640 medium. The cell suspension $(1.0 \mathrm{ml})$ was further incubated in the absence and presence of each compound at $37^{\circ} \mathrm{C}$ for $120 \mathrm{~min}$. The cells were collected by centrifugation, washed with phosphate-buffered saline $\left(137 \mathrm{~mm} \mathrm{NaCl}, 8.1 \mathrm{~mm} \mathrm{Na} \mathrm{NPO}_{4} \cdot 12 \mathrm{H}_{2} \mathrm{O}, 2.68 \mathrm{mM} \mathrm{KCl}, 1.47 \mathrm{~mm}\right.$ $\mathrm{KH}_{2} \mathrm{PO}_{4}, \mathrm{pH}$ 7.4) (PBS) and suspended in $100 \mu \mathrm{l}$ of PBS. The fluorescence intensities of the cell samples $\left(1 \times 10^{7}\right.$ cells $)$ were measured using the Tecan GENios fluorescence detector (Männedorf, Switzerland) at excitation and emission wavelengths of 480 and $530 \mathrm{~nm}$, respectively. The arbitrary units were derived directly from the fluorescence intensity.

\section{Assay of plasma membrane phospholipid peroxidation}

The extent of plasma membrane phospholipid peroxidation was determined using a florescence probe, diphenyl-1-pyrenylphosphine (DPPP) and $t$-butyl hydroperoxide $(t-\mathrm{BOOH})$ as a positive control as follows. ${ }^{22}$ Cells from the overnight culture in YPD medium were collected by centrifugation, washed with PBS and suspended in PBS at a final cell density of $3 \times 10^{7} \mathrm{cells} \mathrm{m}^{-1}$. After the addition of DPPP at a concentration of $50 \mu \mathrm{M}$ and incubation for $10 \mathrm{~min}$ in the dark, the cells were collected by centrifugation, washed twice with PBS and finally suspended in RPMI 1640 medium at a final cell density of $1 \times 10^{7}$ cells ml ${ }^{-1}$. The cell suspension was further incubated in the absence and presence of each compound at $37^{\circ} \mathrm{C}$ for $120 \mathrm{~min}$. The fluorescence intensities of the cell samples $\left(1 \times 10^{6}\right.$ cells $)$ were measured using the FP1520 S fluorescence detector (Jasco, Tokyo, Japan) at excitation and emission wavelengths of 351 and $380 \mathrm{~nm}$, respectively. The arbitrary units were derived directly from the fluorescence intensity.

\section{Measurement of AmB content by HPLC}

Cells from the overnight culture in YPD medium were collected by centrifugation, washed twice with PBS and suspended in PBS to obtain a final cell density of $1 \times 10^{8}$ cells ml ${ }^{-1}$. The cell suspension in PBS was incubated with $20 \mu \mathrm{M} \mathrm{AmB}$ in the absence and presence of $120 \mu \mathrm{m}$ allicin at $37^{\circ} \mathrm{C}$ for $60 \mathrm{~min}$. The supernatant obtained after the removal of cells by centrifugation was used as the supernatant fraction. The cell pellets were washed twice with PBS by repeated centrifugation and then suspended in PBS at a cell density of $1 \times 10^{8}$ cells ml ${ }^{-1}$; the cells were incubated after the addition of Yeast Lytic Enzyme at a final concentration of $6 \mathrm{mg} \mathrm{ml}^{-1}$ and $0.5 \% 2$-mercaptoethanol at $30^{\circ} \mathrm{C}$ with gentle agitation for $60 \mathrm{~min}$ or longer to ensure complete cell lysis. The supernatant obtained after centrifugation $\left(5000 \mathrm{~g}, 10 \mathrm{~min}, 4^{\circ} \mathrm{C}\right)$ of the cell 
lysate was used as the cytoplasmic fraction. The pellets were washed twice with PBS by repeated centrifugation, and the final precipitate obtained (plasma membrane phospholipids) was decomposed by repeated vortexing with a mixture of water/methanol/chloroform (30:20:50, v/v) at room temperature. The upper water-soluble layer was used as the plasma membrane fraction.

These fractions were assayed for AmB content by HPLC with a reverse-phase column ( 4.6 by $250 \mathrm{~mm}$, COSMOSIL $5 \mathrm{C}_{18}$-MS-II, Nacalai Tesque Inc., Kyoto, Japan). The chromatographic solvents were eluted at room temperature with a mobile phase consisting of a mixture of $0.1 \mathrm{M}$ sodium acetate $(\mathrm{pH} 4.0) /$ acetonitrile $(60: 40, \mathrm{v} / \mathrm{v})$ at a flow rate of $1.2 \mathrm{ml} \mathrm{min}^{-1}$. AmB was detected at $405 \mathrm{~nm}^{23}$

\section{Detection of ergosterol}

The subcellular localization of ergosterol was analyzed by its visualization with filipin III as a selective fluorescent prove according to the previously described method. ${ }^{15}$ Cells from the overnight culture in YPD medium were collected by centrifugation, washed twice with RPMI 1640 medium and suspended in the medium to obtain a final cell density of $1 \times 10^{7}$ cells ml ${ }^{-1}$. Cells were then incubated in the absence and presence of each compound with vigorous shaking at $37^{\circ} \mathrm{C}$, and fixed with the addition of $3 \%$ paraformaldehyde at room temperature for $10 \mathrm{~min}$. The fixed cells were collected by centrifugation, washed with distilled water and incubated in the dark with $50 \mu \mathrm{g} \mathrm{ml}^{-1}$ filipin III at $30^{\circ} \mathrm{C}$ for $15 \mathrm{~min}$. Cells were then observed under a phase-contrast microscope and a fluorescence microscope with excitation at $338 \mathrm{~nm}$ and emission at $480 \mathrm{~nm}$.

\section{Preparation of ergosterol-enriched cells}

For measurement of cell growth and vacuole staining, cells from the overnight culture in YPD medium were inoculated into a freshly prepared YPD medium containing $240 \mu \mathrm{M}$ ergosterol at a cell density of $1 \times 10^{7} \mathrm{cells} \mathrm{ml}^{-1}$, and incubated with vigorous shaking at $30^{\circ} \mathrm{C}$ for $60 \mathrm{~min}$. For vacuole isolation, cells from the overnight culture in YPD medium were inoculated into a freshly prepared YPD medium containing $500 \mu \mathrm{M}$ ergosterol at a cell density of $1 \times 10^{9} \mathrm{cells} \mathrm{m}^{-1}$, and incubated with vigorous shaking at $30^{\circ} \mathrm{C}$ for $60 \mathrm{~min}$. For HPLC-analysis of $\mathrm{AmB}$, cells from the overnight culture in YPD medium were inoculated into a freshly prepared YPD medium containing $370 \mu \mathrm{M}$ ergosterol at a cell density of $1 \times 10^{8} \mathrm{cells} \mathrm{ml}^{-1}$, and incubated with vigorous shaking at $30^{\circ} \mathrm{C}$ for $60 \mathrm{~min}$. These ergosterol-enriched cells were treated exactly in the same way as untreated cells in each of the above experiments.

\section{Chemicals}

The chemicals were obtained from the following sources: AmB and filipin III, Sigma Aldrich (St Louis, MO, USA); allicin, LKT Laboratories Inc. (St Paul, MN, USA); FM4-64 and DCFH-DA, Molecular Probe (Eugene, OR, USA); DPPP, Dojindo (Kumamoto, Japan); Ficoll 400, Alfa Aesar (Ward Hill, MA, USA); Yeast Lytic Enzyme, ICN Biomedicals (Aurora, OH, USA). The other chemicals used were of analytical reagent grade and purity.

\section{RESULTS}

\section{Enhancement effect of allicin on AmB lethality}

We first examined whether allicin could enhance AmB lethality against C. albicans cells by determining the changes in cell viability. AmB showed a highly lethal effect at $2 \mu \mathrm{M}$ and even at the non-lethal concentration of $0.25 \mu \mathrm{M}$ in combination with $120 \mu \mathrm{M}$ allicin (Figure 2); these lethal concentrations were comparable with the concentration that effectively induced cell death of $S$. cerevisiae in distilled water. ${ }^{8}$

\section{Effects of AmB and allicin, and their combination on ROS production and plasma membrane phospholipid peroxidation} Allicin may not enhance AmB lethality by increasing AmB-induced oxidative stress in C. albicans cells in RPMI 1640 medium at $37^{\circ} \mathrm{C}$. As shown in Figure 3a, the level of ROS production was maintained at the control level when the cells were treated with allicin at $120 \mu \mathrm{m}$ or AmB at the non-lethal concentration of $0.25 \mu \mathrm{M}$. We did not observe a

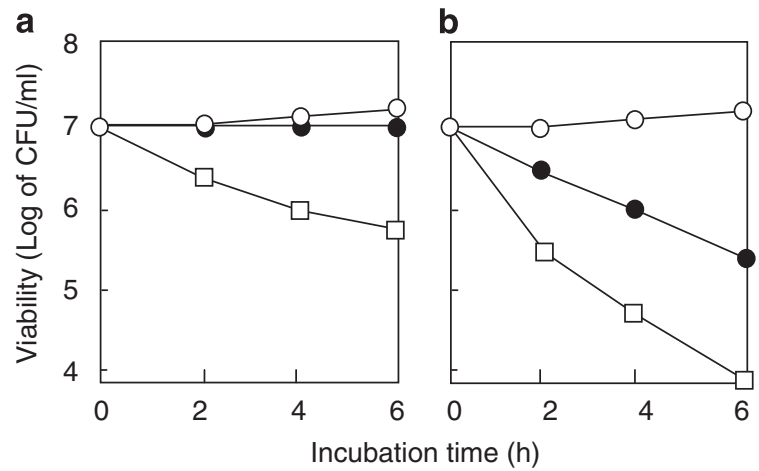

Figure 2 The effects of $A m B$ on the viability of $C$. albicans cells in the absence (a) and presence of allicin (b). For (A), cells $\left(1 \times 10^{7}\right.$ cells $\left.\mathrm{ml}^{-1}\right)$ were incubated in RPMI 1640 medium containing $A m B$ at $0 \mu \mathrm{m}(O)$, $0.25 \mu \mathrm{m}(\bullet)$ and $2 \mu \mathrm{m}(\square)$ at $37^{\circ} \mathrm{C}$. For (b), cells $\left(1 \times 10^{7}\right.$ cells ml $\left.{ }^{-1}\right)$ were incubated in RPMI 1640 medium containing $120 \mu \mathrm{m}$ allicin and AmB at $0 \mu \mathrm{m}(O), 0.25 \mu \mathrm{m}(\bullet)$ and $2 \mu \mathrm{m}(\square)$ at $37^{\circ} \mathrm{C}$.
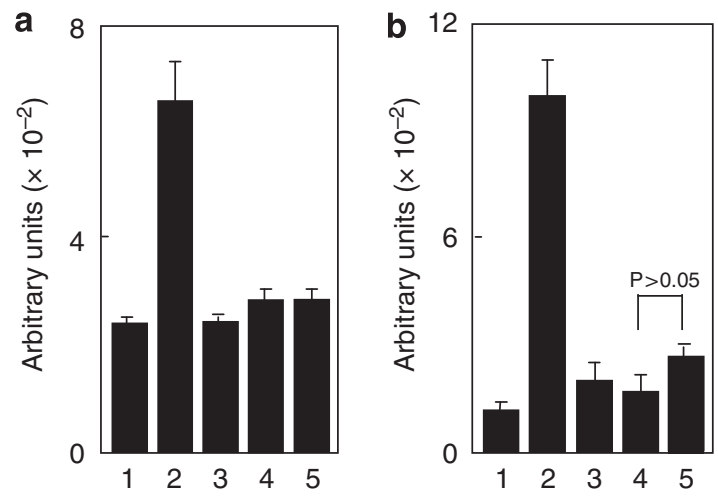

Figure 3 The effects of AmB, allicin and their combination on ROS production (a) and plasma membrane phospholipid peroxidation (b). For (a), cells $\left(1 \times 10^{7}\right.$ cells $\left.\mathrm{ml}^{-1}\right)$ were incubated in RPMI 1640 medium containing none (1), $25 \mu \mathrm{m}$ FOH (2), $120 \mu \mathrm{m}$ allicin (3), $0.25 \mu \mathrm{m} \mathrm{AmB} \mathrm{(4)} \mathrm{and} \mathrm{a}$ combination of $0.25 \mu \mathrm{m} \mathrm{AmB}$ and $120 \mu \mathrm{m}$ allicin (5) at $37^{\circ} \mathrm{C}$ for $120 \mathrm{~min}$. For (b), cells $\left(1 \times 10^{7}\right.$ cells ml-1) were incubated in RPMI 1640 medium containing none (1), $1 \mathrm{~mm} \mathrm{t-BOOH} \mathrm{(2),} 120 \mu \mathrm{m}$ allicin (3), $0.25 \mu \mathrm{m} \mathrm{AmB} \mathrm{(4)}$ and a combination of $0.25 \mu \mathrm{m} \mathrm{AmB}$ and $120 \mu \mathrm{m}$ allicin (5) at $37^{\circ} \mathrm{C}$ for $120 \mathrm{~min}$. Data are expressed as the mean \pm s.d. of the arbitrary units measured in triplicate assays, and are analyzed by Student's $t$-test. $P<0.05$ is considered statistically significant.

significant difference in the level of ROS production when the cells were simultaneously treated with both $\mathrm{AmB}$ and allicin.

Allicin was found to accelerate plasma membrane phospholipid peroxidation in S. cerevisiae when the cells were incubated in distilled water at $30^{\circ} \mathrm{C} .{ }^{8}$ We therefore examined the relationship between plasma membrane phospholipid peroxidation and the enhancement effect of allicin on AmB lethality against C. albicans cells in RPMI 1640 medium at $37^{\circ} \mathrm{C}$. The levels of plasma membrane phospholipid peroxidation were not significantly increased when cells were incubated with either allicin or AmB alone at a non-lethal concentration $(0.25 \mu \mathrm{M})$ (Figure $3 \mathrm{~b})$. Allicin was ineffective in increasing the level of such a cell surface oxidative event that was detected at the control level in AmB-treated cells. These results suggested the involvement of another toxic event in the enhancement effect of allicin on AmB lethality against C. albicans cells in RPMI 1640 medium at $37^{\circ} \mathrm{C}$. 

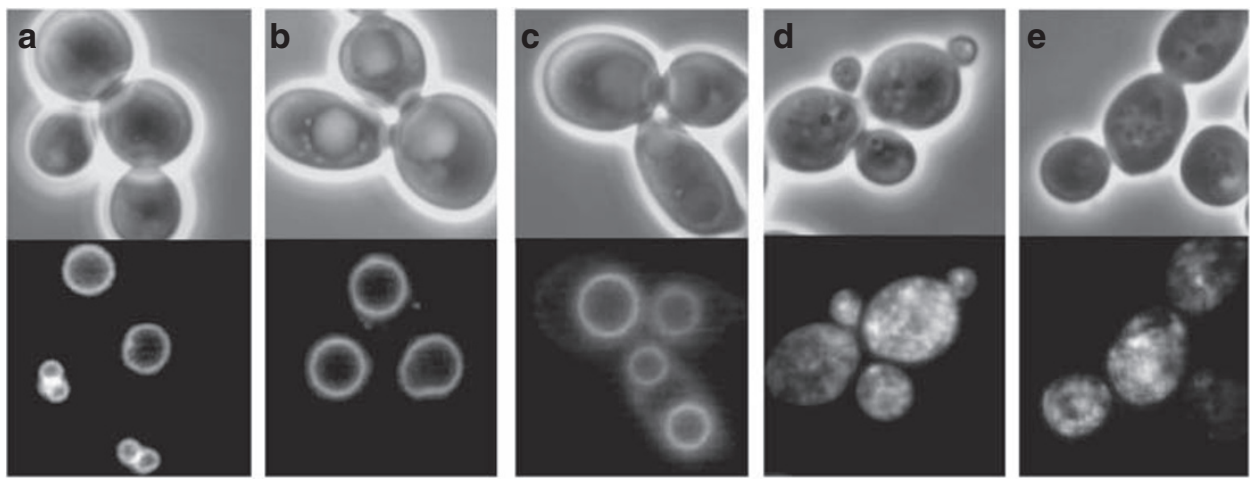

Figure 4 The effects of AmB, allicin and their combination on vacuole morphology in C. albicans cells. After treatment with the fluorescent dye FM4-64, cells $\left(1 \times 10^{7}\right.$ cells ml $\left.^{-1}\right)$ were incubated in RPMI 1640 medium containing none (a), $120 \mu \mathrm{m}$ allicin (b), $0.25 \mu \mathrm{m} \mathrm{AmB} \mathrm{(c),} 2 \mu \mathrm{m} \mathrm{AmB} \mathrm{(d)} \mathrm{and} \mathrm{a} \mathrm{combination}$ of $0.25 \mu \mathrm{m} \mathrm{AmB}$ and $120 \mu \mathrm{m}$ allicin (e) at $37^{\circ} \mathrm{C}$ for $60 \mathrm{~min}$. Cells were observed under a bright-field microscope (top) and a fluorescence microscope (bottom).

\section{Enhancement effect of allicin on vacuole disruption by AmB}

Vacuole disruption was observed when $S$. cerevisiae cells were treated with a lethal concentration of $\mathrm{AmB}$ in distilled water in which cells are more susceptible to the lethal action of the antibiotic than in a medium. ${ }^{8}$ We therefore examined whether AmB treatment can trigger vacuole disruption in C. albicans cells maintained in RPMI 1640 medium at $37^{\circ} \mathrm{C}$. The vacuoles appeared as membrane-enclosed spherical structures in untreated cells although they were smaller in size as compared with those in S. cerevisiae cells (Figure 4a). No morphological changes were observed in the organelles of the cells incubated in the medium containing $120 \mu \mathrm{m}$ allicin (Figure $4 \mathrm{~b}$ ). Furthermore, AmB did not exert disruptive effects on the organelles at the non-lethal concentration $(0.25 \mu \mathrm{M})$, but caused serious structural damages when administered at the lethal concentration $(2 \mu \mathrm{M})$ (Figures $4 \mathrm{c}$ and $\mathrm{d}$ ). In combination with allicin, AmB showed a similar vacuole disruptive activity even at non-lethal concentration $(0.25 \mu \mathrm{M})$ in parallel to the enhancement of its lethality (Figures $2 \mathrm{~b}$ and $4 \mathrm{e}$ ).

Effects of allicin on AmB-induced cell death and vacuole disruption in ergosterol-enriched cells

Our previous study suggested that allicin inhibits ergosterol transport from the plasma membrane to the vacuole membrane when S. cerevisiae cells were treated with $\mathrm{AmB}$ in distilled water. ${ }^{15}$ Thus, ergosterol transport is considered to be a cellular response to protect the fungal vacuoles against the disruptive action of AmB. As observed in the case of S. cerevisiae cells, ergosterol-enriched C. albicans cells were completely resistant to the lethal effects of $\mathrm{AmB}$ at $2 \mu \mathrm{M}$ or at $0.25 \mu \mathrm{M}$ in combination with $120 \mu \mathrm{M}$ allicin, though the fungal cell growth was inhibited under each of these conditions (Figure 5a). In agreement with the maintenance of cell viability, the vacuoles of ergosterol-enriched cells were observed to be normal spherical structures in the medium containing $\mathrm{AmB}$ at the lethal concentration $(2 \mu \mathrm{M})$ and at a non-lethal concentration $(0.25 \mu \mathrm{M})$ in combination with allicin (Figure 5b).

\section{Direct disruption of isolated vacuoles by AmB}

We examined whether AmB could directly disrupt the vacuoles isolated from C. albicans cells. The vacuoles isolated from intact cells were observed with the swollen spherical structures after incubation with $10 \mu \mathrm{M} \mathrm{AmB}$, whereas the organelles were mostly disrupted into amorphous fragments or particles with increasing concentration of the antibiotic up to $20 \mu \mathrm{m}$ (Figures $6 \mathrm{a}$ and c). Allicin did not a

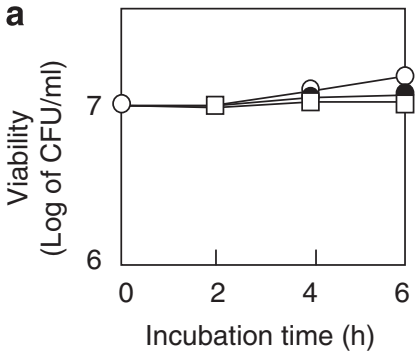

b

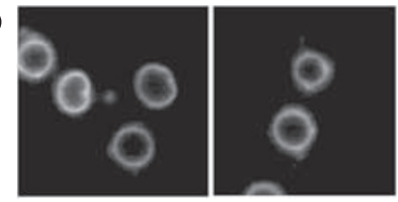

Figure $5 \mathrm{AmB}$-induced lethality (a) and vacuole disruption (b) in ergosterolenriched $C$. albicans cells. For (a), ergosterol-enriched cells $\left(1 \times 10^{7}\right.$ cells ml $\left.{ }^{-1}\right)$ were incubated in RPMI 1640 medium containing none $(O), 2 \mu \mathrm{m} \mathrm{AmB} \mathrm{( \bullet ),}$ and a combination of $0.25 \mu \mathrm{m} \mathrm{AmB}$ and $120 \mu \mathrm{m}$ allicin ( $\square$ ) at $37^{\circ} \mathrm{C}$. For (b), ergosterol-enriched cells $\left(1 \times 10^{7}\right.$ cells ml $\left.{ }^{-1}\right)$ were incubated in RPMI 1640 medium containing $2 \mu \mathrm{m} \mathrm{AmB}$ (left) and a combination of $0.25 \mu \mathrm{m}$ AmB and $120 \mu \mathrm{m}$ allicin (right) at $37^{\circ} \mathrm{C}$ for $60 \mathrm{~min}$. Cells were observed under a fluorescence microscope.

stimulate or inhibit AmB-induced vacuole disruption, indicating that this compound does not contribute to the direct interaction between the antibiotic and the fungal vacuole (Figures $6 \mathrm{~b}$ and $\mathrm{d}$ ). The vacuoles isolated from ergosterol-enriched cells were completely resistant to the disruptive action of $20 \mu \mathrm{M} \mathrm{AmB}$ both in the absence and presence of allicin. These findings agreed with our idea that allicin can enhance the fungicidal activity of $\mathrm{AmB}$ against $C$. albicans by inhibiting intracellular ergosterol transport, a cellular response to protect against vacuole disruption by $\mathrm{AmB}$, as observed in the case of S. cerevisiae. ${ }^{15}$

\section{Effect of allicin on cellular uptake of AmB}

The enhancement effect of allicin on AmB-induced vacuole disruption also suggests that allicin enhances cellular uptake of the antibiotic into the cytoplasm of $C$. albicans cells via diffusion through the plasma membrane or a transporter-mediated incorporation. Ergosterolenriched cells are likely to be more resistant to AmB than untreated cells because of its specific binding with ergosterol that may also be 

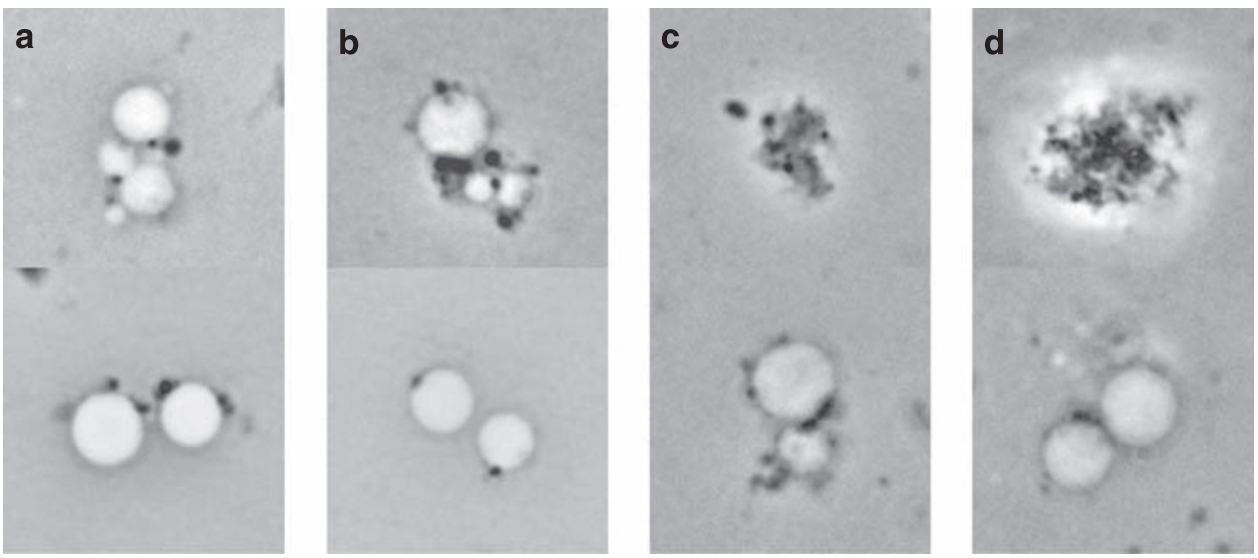

Figure 6 The disruptive effects of AmB, allicin and their combination on isolated vacuoles obtained from C. albicans cells. Vacuoles from untreated (top) and ergosterol-enriched cells (bottom) were incubated with $10 \mu \mathrm{m}(\mathbf{a}, \mathbf{b})$ and $20 \mu \mathrm{m} \mathrm{AmB} \mathrm{(c,} \mathrm{d),} \mathrm{respectively,} \mathrm{in} \mathrm{the} \mathrm{absence} \mathrm{(a,} \mathrm{c)} \mathrm{and} \mathrm{presence} \mathrm{of} 120 \mu \mathrm{m}$ allicin (b, d) at $37^{\circ} \mathrm{C}$ for $60 \mathrm{~min}$. Vacuoles were observed under a bright-field microscope.

Table 1 Subcellular localization of AmB in C. albicans cells

\begin{tabular}{lcccc}
\hline & & \multicolumn{3}{c}{$A m B$ content $(n m o l)^{\mathrm{a}}$ in } \\
\cline { 3 - 5 } Cells & Addition of allicin & Supernatant & $\begin{array}{c}\text { Plasma } \\
\text { membrane }\end{array}$ & Cytoplasm \\
\hline \multirow{2}{*}{ Untreated } & - & $1.0 \pm 0.2$ & $16.2 \pm 0.3$ & $2.6 \pm 0.3^{\mathrm{b}}$ \\
& + & $0.5 \pm 0.2$ & $16.1 \pm 0.6$ & $2.4 \pm 0.2^{\mathrm{b}}$ \\
Ergosterol-enriched & - & $0.5 \pm 0.1$ & $16.5 \pm 1.1$ & $2.3 \pm 0.2^{\mathrm{b}}$ \\
& + & $0.3 \pm 0.1$ & $16.7 \pm 1.1$ & $2.2 \pm 0.2^{\mathrm{b}}$ \\
& & + & 0.3 &
\end{tabular}

Data are expressed as the mean \pm s.d. of the $A m B$ content in each fraction measured in triplicate assays. The AmB content of each cytoplasmic fraction is statistically analyzed by Student's $t$-test, in which $\mathrm{P}<0.05$ is considered statistically significant.

aThe total quantity of AmB initially added to the assay mixture $(1.0 \mathrm{ml})$ was $20 \mathrm{nmol}$.

${ }^{b}$ No significant difference between each of these values.

enriched in the plasma membrane. We thus examined the effects of allicin on subcellular localization of AmB by measuring its contents in various fractions obtained from untreated and ergosterol-enriched cells. In this experiment, the concentrations of $\mathrm{AmB}$ and allicin were increased up to 20 and $240 \mu \mathrm{M}$, respectively, with increasing cell density up to $1 \times 10^{8}$ cells $\mathrm{ml}^{-1}$ owing to the sensitivity of HPLC analysis. In untreated cells, AmB was mostly absent in the supernatant of the cell suspension when incubated with $\mathrm{AmB}$ alone for $60 \mathrm{~min}$, and it was detected in the plasma membrane fraction at a ratio of more than $80 \%$ of the initial quantity that was added to the cells (Table 1). This can be explained by the binding of AmB to plasma membrane ergosterol. The remaining antibiotic was quantitatively recovered from the cytoplasmic fraction; this confirmed its penetration across the plasma membrane and into the cytoplasm. Apart from the finding that allicin enhanced AmB-induced vacuole disruption, this compound did not influence the subcellular localization of AmB. AmB penetrated into and across the plasma membrane of ergosterolenriched cells as effectively as untreated cells, wherein its subcellular localization pattern remained unchanged both in the absence and presence of allicin.

Effect of allicin on subcellular localization of ergosterol

We finally confirmed the role of allicin in its enhancement effect on the fungicidal activity of $\mathrm{AmB}$ against $C$. albicans in terms of its effect on subcellular localization of ergosterol. As shown in Figure 7, ergosterol was more brightly visualized in the plasma membrane than faintly stained cytoplasm of untreated cells, whereas this molecule was predominantly detected in the cytoplasm when cells are treated with $\mathrm{AmB}$ at a non-lethal concentration (Figures $7 \mathrm{a}$ and $\mathrm{b}$ ). The intracellular localization of ergosterol was more clearly visualized in cells treated with $\mathrm{AmB}$ at a lethal concentration though its mobilization into the cytoplasm failed in protection against the vacuole disruption (Figure 7c). Ergosterol still remained in the plasma membrane when allicin was simultaneously added with $\mathrm{AmB}$ to enhance its vacuole-targeting fungicidal activity (Figure 7d).

\section{DISCUSSION}

It has been widely accepted that the fungicidal activity of $\mathrm{AmB}$ is a result of channel formation across the plasma membrane after the antibiotic selectively binds to ergosterol, thereby enhancing the leakage of intracellular $\mathrm{K}^{+}$and other ionic substances. ${ }^{2-4}$ Oxidative stress induction is also considered to be an AmB-induced cytotoxic event although it remains unclear whether this event is caused by autooxidation or the ionophoric property of the antibiotic. ${ }^{2}$ We previously reported that allicin enhances the fungicidal activity of $\mathrm{Cu}^{2+}$ against S. cerevisiae in distilled water where the fungal cells are rendered extremely sensitive to this divalent cation. ${ }^{24} \mathrm{Cu}^{2+}$-induced toxicity is characterized by intracellular ROS production, plasma membrane peroxidation and subsequent damage due to plasma membrane disruption, but the enhancement effect of allicin on this event was not simply elucidated by the enhancement of oxidative stress induction. ${ }^{25}$ This also suggested the involvement of a lethal event other than plasma membrane phospholipid peroxidation in the enhancement effect of allicin on AmB lethality against C. albicans. On the other hand, An et al. ${ }^{16}$ attempted to use allicin in AmB-dependent chemotherapy for candidiasis, but insisted that allicin enhances AmBinduced plasma membrane phospholipid peroxidation in C. albicans cells. Unlike the case with its invasive growth in mammalian organs, however, the in vitro experiment in the above-mentioned study was conducted under a hypoosmotic condition where the metabolic pathways, which are usually not activated under the normal growth condition, may be activated in C. albicans cells. This study is thus expected to provide more reliable evidence of AmB lethality as well as its enhancement by allicin against C. albicans cells in RPMI 1640 medium at $37^{\circ} \mathrm{C}$. 

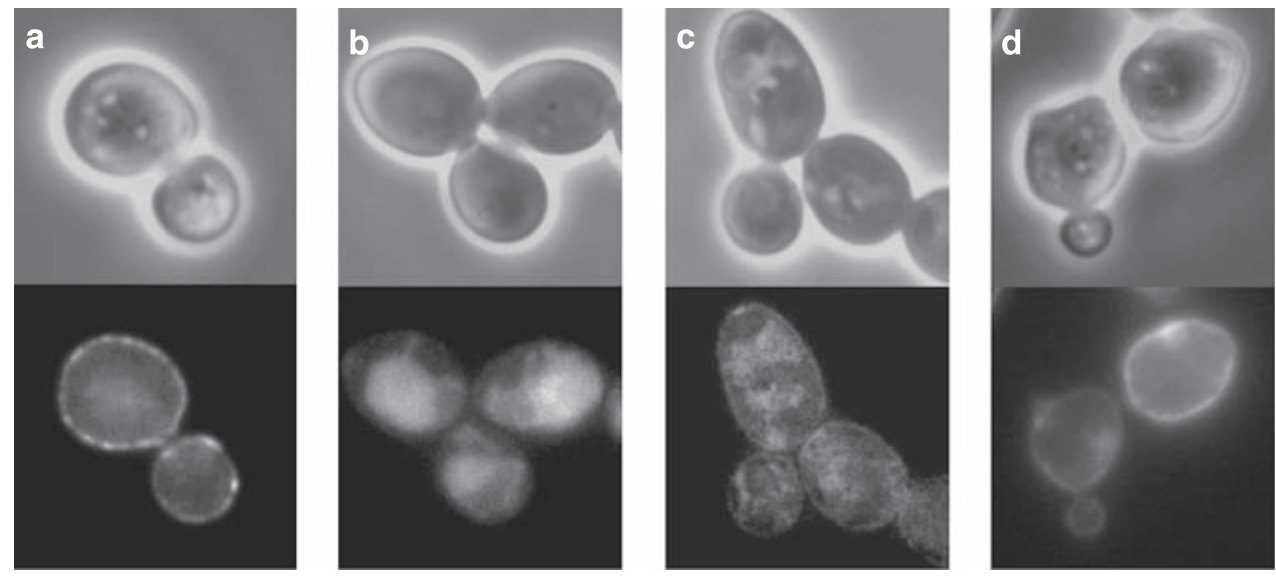

Figure 7 The effect of allicin on subcellular localization of ergosterol in C. albicans cells. Cells $\left(1 \times 10^{7} \mathrm{ml}^{-1}\right)$ were incubated in RPMI 1640 medium containing none (a), $0.25 \mu \mathrm{m} \mathrm{AmB} \mathrm{(b),} 2 \mu \mathrm{m} \mathrm{AmB} \mathrm{(c)} \mathrm{and} \mathrm{a} \mathrm{combination} \mathrm{of} 0.25 \mu \mathrm{m} \mathrm{AmB}$ and $120 \mu \mathrm{m}$ allicin (d) at $37^{\circ} \mathrm{C}$ for $60 \mathrm{~min}$. Cells were then fixed with $3 \%$ paraformaldehyde, incubated with $50 \mu \mathrm{g} \mathrm{ml}^{-1}$ filipin III, and observed under a phase-contrast microscope (top) and a fluorescence microscope (bottom).

Vacuoles are organelles that are involved in osmoregulation, ion homeostasis and cell volume regulation in fungal cells. ${ }^{26,27}$ Various hydrolytic enzymes, including proteases and nucleases, are thought to accumulate in vacuoles; hence, the damage to these organelles is considered to be a critical step in cell death induction. ${ }^{28}$ In addition, the sudden loss of vacuoles would result in increased sensitivity to osmotic imbalance in the cytoplasm, especially in cells with impaired plasma membrane ion transport. Vacuole disruption was observed in S. cerevisiae cells treated with the polyene macrolide antibiotic niphimycin (NM) characterized by a macrocyclic lactone ring containing alkylguanidium. ${ }^{29}$ A synthetic analog of this side chain could also render S. cerevisiae cells sensitive to the lethal effects of AmB, and this effect was indeed accompanied by enhanced vacuole disruption. PMB is a bactericidal antibiotic that can selectively inhibit the growth of Gram-negative bacteria by altering bacterial plasma membrane permeability and is weakly effective against fungal strains such as S. cerevisiae. ${ }^{13,14}$ Alternatively, allicin can enhance the fungicidal activity of PMB against S. cerevisiae and other fungal strains, including filamentous fungi such as Aspergillus fumigatus. ${ }^{13}$ The enhancement of the fungicidal activity of PMB by allicin was accompanied by enhanced vacuole disruption. As deduced from the similarity in the modes of action of $\mathrm{AmB}$, niphimycin and $\mathrm{PMB}$ on ion transport through the plasma membrane, the vacuole disruptive activities of these antibiotics are likely to depend on cellular osmotic imbalance because of the leakage of $\mathrm{K}^{+}$in addition to their direct disruptive actions on the organelles. To our knowledge, this study is the first of its kind to reveal that enhanced vacuole disruption induced by $\mathrm{AmB}$ at a lethal concentration $(2 \mu \mathrm{M})$ and at a non-lethal concentration $(0.25 \mu \mathrm{M})$ in combination with allicin could be lethal against the pathogenic fungus $C$. albicans.

The vacuoles isolated from $C$. albicans cells are subjected to the direct disruptive action of the antibiotic at the lower concentration than is needed for disruption of the organelles from S. cerevisiae cells. However, there has been no clear evidence on the cellular uptake of $\mathrm{AmB}$ across the plasma membrane and into the cytoplasm. Although the enhancement of AmB-induced vacuole disruption by allicin is independent of this process, we for the first time demonstrated the accumulation of AmB in the cytoplasm of C. albicans cells. The AmB resistance of the ergosterol-enriched cells could therefore be attributed to the elevated resistance of the ergosterol-enriched vacuole rather than an increase in the ergosterol content of the plasma membrane. In spite of such evidence that supports the direct interaction between $\mathrm{AmB}$ and the vacuoles, the concentration of $\mathrm{AmB}$ required for the direct disruptive action on the organelles $(20 \mu \mathrm{M})$ was apparently higher than the extracellular concentration that resulted in vacuole disruption $(2 \mu \mathrm{M})$. The high $\mathrm{AmB}$ concentration for the direct disruptive action may be attributed to the use of concentrated vacuoles in the assay, otherwise this may be elucidated by reduced interaction between $\mathrm{AmB}$ and its molecular target possibly in the vacuole membrane under the hypertonic condition used for the maintenance of vacuole architecture. Filipin III, a polyene macrolide antibiotic, is used as a fluorescent probe to determine the subcellular localization of ergosterol in S. cerevisiae. ${ }^{15}$ This fluorescent probe could visualize ergosterol in the plasma membrane of intact cells and its mobilization into the cytoplasmic compartment in response to AmB treatment. As in the case with S. cerevisiae, the enhancement effect of allicin on AmB lethality as well as vacuole disruption (see Figures $2 \mathrm{~b}$ and $4 \mathrm{e}$ ) was accompanied by the inhibition of ergosterol transport from the plasma membrane into the cytoplasm of C. albicans cells (see Figure $7 \mathrm{~d}$ ). Taking into consideration that ergosterol treatment prevented the enhancement of $\mathrm{AmB}$ lethality by allicin, we propose that allicin enhances the vacuole-targeting fungicidal activity of $\mathrm{AmB}$ against this pathogenic fungus by inhibiting a mechanism of intracellular ergosterol transport.

\section{ACKNOWLEDGEMENTS}

This work was supported in part by a Grant-in-Aid for Scientific Research (C) (No. 20580083) from the Japan Society for the Promotion of Science.

1 Dupont, P. F. Candida albicans, the opportunist A cellular and molecular perspective. J. Am. Podiatr. Med. Assoc. 85, 104-115 (1995).

2 Brajtburg, J., Powderly, W. G., Kobayashi, G. S. \& Medoff, G. Amphotericin B: Current understanding of mechanisms of action. Antimicrob. Agents Chemother. 34, 183-188 (1990).

3 Ellis, D. Amphotericin B: spectrum and resistance. J. Antimicrob. Chemother. 49, 7-10 (2002).

4 Baginski, M., Sternal, K., Czub, J. \& Borowski, E. Molecular modelling of membrane activity of amphotericin $\mathrm{B}$, a polyene macrolide antifungal antibiotic. Acta Biochimica Polonica 52, 655-658 (2005).

5 Alonso, M. A., Vázquez, D. \& Carrasco, L. Compounds affecting membranes that inhibit protein synthesis in yeast. Antimicrob. Agents Chemother. 16, 750-756 (1979). 
6 Chen, W. C., Chou, D. L. \& Feingold, D. S Dissociation between ion permeability and the lethal action of polyene antibiotics on Candida albicans. Antimicrob. Agents Chemother. 13, 914-917 (1978).

7 Okamoto, Y., Aoki, S. \& Mataga, I. Enhancement of amphotericin B activity against Candida albicans by superoxide radical. Mycopathologia 158, 9-15 (2004).

8 Ogita, A., Fujita, k., Taniguchi, M. \& Tanaka, T. Enhancement of the fungicidal activity of amphotericin B by allicin, an allyl-sulfur compound from garlic, against the yeast Saccharomyces cerevisiae as a model system. Planta Med. 72, 1247-1250 (2006).

9 Ankri, S. \& Mirelman, D. Antimicrobial properties of allicin from garlic. Microbes Infect. 1, 125-119 (1999).

10 Oommen, S., Anto, J. R., Srinivas, G. \& Karunagaran, D. Allicin (from garlic) induces caspase-mediated apoptosis in cancer cells. Eur. J. Pharmacol. 485, 97-103 (2004).

11 Briggs, W. H., Xiao, H., Parkin, K. L., Shen, C. \& Goldman, I. L Differential inhibition of human platelet aggregation by selected Allium thiosulfinates. J. Agric. Food Chem. 48 5731-5735 (2000).

12 Gebhardt, R. \& Beck, H. Differential inhibitory effects of garlic-derived organosulfur compounds on cholesterol biosynthesis in primary rat hepatocyte cultures. Lipids. $\mathbf{3 1}$ 1269-1276 (1996).

13 Ogita, A., Nagao, Y., Fujita, K. \& Tanaka, T. Amplification of vacuole-targeting fungicidal activity of antibacterial antibiotic polymyxin B by allicin, an allyl sulfur compound from garlic. J. Antibiot. 60, 511-518 (2007)

14 Ogita, A., Konishi, Y., Borjihan, B., Fujita, K. \& Tanaka, T. Synergistic fungicidal activities of polymyxin $B$ and ionophores, and their dependence on direct disruptive action of polymyxin B on fungal vacuole. J. Antibiot 62, 81-87 (2009).

15 Ogita, A., Fujita, K. \& Tanaka, T. Enhancement of the fungicidal activity of amphotericin B by allicin: Effects on intracellular ergosterol trafficking. Planta Med. 75, 222-226 (2009).

$16 \mathrm{An}, \mathrm{M}$. et al. Allicin enhances the oxidative damage effect of amphotericin B against Candida albicans. Int. J. Antimicrob. Agents 33, 258-263 (2008).

$17 \mathrm{Cruz}$, M. C. et al. Calcineurin is essential for survival during membrane stress in Candida albicans. EMBO J 21, 546-549 (2002).

18 Bryant, N. J. \& Stevens, T. H. Vacuole biogenesis in Saccharomyces cerevisiae: protein transport pathways to the yeast vacuole. Microbiol. Mol. Biol. Rev. 62, 230-247 (1998).
19 Ohsumi, Y. \& Anraku, Y. Active transport of basic amino acids driven by a proton motive force in vacuolar membrane vesicles of Saccharomyces cerevisiae. J. Biol. Chem. 256, 2079-2082 (1981).

20 Tabuchi, M. et al. Vacuolar protein sorting in fission yeast: cloning, biosynthesis, transport, and processing of carboxypeptidase $Y$ from Schizosaccharomyces pombe. J. Bacteriol. 179, 4179-4189 (1997).

21 Machida, K., Tanaka, T., Fujita, K. \& Taniguchi, M. Farnesol-induced generation of reactive oxygen species via indirect inhibition of mitochondrial electron transport chain in the yeast Saccharomyces cerevisiae. J. Bacteriol. 180, 4460-4465 (1998).

22 Takahashi, M., Shibata, M. \& Niki, E. Estimation of lipid peroxidation of live cells using a fluorescent probe, iphenyl-1-pyrenylphosphine. Free Radic. Biol. Med. 31, 164-174 (2001).

23 Esposito, E., Bortolotti, F., Menegatti, E. \& Cortesi, R. Amphiphilic association systems for amphotericin B delivery. Int. J. Pharm. 260, 249-260 (2003).

24 Ogita, A. et al. Synergistic fungicidal activity of $\mathrm{Cu}^{2+}$ and allicin, an allyl sulfur compound from garlic, and its relation to the role of alkyl hydroperoxide reductase 1 as a cell surface defense in Saccharomyces cerevisiae. Toxicology. 215, 205-213 (2005).

25 Ogita, A., Fujita, K., Taniguchi, M. \& Tanaka, T. Dependence of synergistic fungicidal activity of $\mathrm{Cu}^{2+}$ and allicin, an allyl sulfur compound from garlic, on selective accumulation of the ion in the plasma membrane fraction via allicin-mediated phospholipid peroxidation. Planta Med. 72, 875-880 (2006).

26 Thumm, M. Structure and function of the yeast vacuole and its role in autophagy. Microsc. Res. Tech. 51, 563-572 (2000).

27 Wickner, W. Yeast vacuoles and membrane fusion pathways. EMBO J. 21, 1241-1247 (2002).

28 Obara, K., Kuriyama, H. \& Fukuda, H. Direct evidence of active and rapid nuclear degradation triggered by vacuole rupture during programmed cell death in Zinnia. Plant Physiol. 125, 615-626 (2001).

29 Ogita, A. et al. Synergistic fungicidal activities of amphotericin B and $\mathrm{N}$-methyl$N^{\prime \prime}$-dodecylguanidine: a constituent of polyol macrolide antibiotic niphimycin. J. Antibiot. 60, 27-35 (2007). 